(2) OPEN ACCESS

\title{
Occupational socioeconomic risk associations for head and neck cancer in Europe and South America: individual participant data analysis of pooled case- control studies within the INHANCE Consortium
}

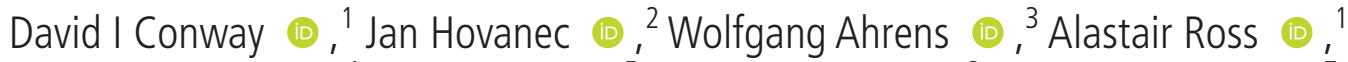 \\ Ivana Holcatova (1), ${ }^{4}$ Pagona Lagiou, ${ }^{5}$ Diego Serraino (1), ${ }^{6}$ Cristina Canova (1) ${ }^{7}$ \\ Lorenzo Richiardi (1), ${ }^{8}$ Claire Healy 다, ${ }^{9}$ Kristina Kjaerheim (ㄷ), ${ }^{10}$

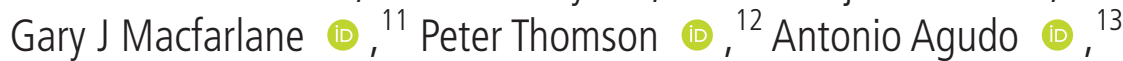 \\ Ariana Znaor (1) , ${ }^{14}$ Paul Brennan, ${ }^{14}$ Danièle Luce (ㄷ), ${ }^{15,16,17}$ Gwenn Menvielle (ㄷ), ${ }^{18}$ \\ Isabelle Stucker, ${ }^{19,20}$ Simone Benhamou (i), ${ }^{21}$ Heribert Ramroth (1) , ${ }^{22}$ \\ Paolo Boffetta (1) , ${ }^{23,24}$ Marta Vilensky, ${ }^{25}$ Leticia Fernandez, ${ }^{26}$ \\ Maria Paula Curado (1), ${ }^{27}$ Ana Menezes (1), ${ }^{28}$ Alexander Daudt, ${ }^{29}$ \\ Rosalina Koifman (10 ${ }^{30}$ Victor Wunsch-Filho, ${ }^{31}$ Amy Lee Yuan-Chin, ${ }^{32}$ Mia Hashibe, ${ }^{33}$ \\ Thomas Behrens ${ }^{\circ},{ }^{2}$ Alex D McMahon
}

- Additional material is published online only. To view please visit the journal online (http://dx.doi.org/10.1136/ jech-2020-214913)

For numbered affiliations see end of article.

Correspondence to Prof David I Conway, School of Medicine, Dentistry, and Nursing, University of Glasgow, Glasgow G12 8QQ, UK; David.Conway@glasgow.ac.uk

Dr Isabelle Stucker is since deceased.

Received 30 June 2020 Revised 22 November 2020 Accepted 4 January 2021 Published Online First 23 February 2021

Check for updates

(C) Author(s) (or their employer(s)) 2021. Re-use permitted under CC BY-NC. No commercial re-use. See rights and permissions. Published by BMJ.

To cite: Conway DI,

Hovanec J, Ahrens W, et al. J

Epidemiol Community Health 2021:75:779-787.

\section{ABSTRACT}

Background The association between socioeconomic disadvantage (low education and/or income) and head and neck cancer is well established, with smoking and alcohol consumption explaining up to three-quarters of the risk. We aimed to investigate the nature of and explanations for head and neck cancer risk associated with occupational socioeconomic prestige (a perceptual measure of psychosocial status), occupational socioeconomic position and manual-work experience, and to assess the potential explanatory role of occupational exposures.

Methods Pooled analysis included 5818 patients with head and neck cancer (and 7326 control participants) from five studies in Europe and South America. Lifetime job histories were coded to: (1) occupational social prestige-Treiman's Standard International Occupational Prestige Scale (SIOPS); (2) occupational socioeconomic position-International Socio-Economic Index (ISEI); and (3) manual/non-manual jobs.

Results For the longest held job, adjusting for smoking, alcohol and nature of occupation, increased head and neck cancer risk estimates were observed for low SIOPS $\mathrm{OR}=1.88(95 \% \mathrm{Cl}: 1.64$ to 2.17$)$, low ISEI OR=1.74 (95\% Cl: 1.51 to 1.99) and manual occupations $\mathrm{OR}=1.49$ (95\% Cl: 1.35 to 1.64). Following mutual adjustment by socioeconomic exposures, risk associated with low SIOPS remained OR=1.59 (95\% Cl: 1.30 to 1.94).

Conclusions These findings indicate that low occupational socioeconomic prestige, position and manual work are associated with head and neck cancer, and such risks are only partly explained by smoking, alcohol and occupational exposures. Perceptual occupational psychosocial status (SIOPS) appears to be the strongest socioeconomic factor, relative to socioeconomic position and manual/non-manual work.

\section{INTRODUCTION}

Globally, head and neck cancers, comprising cancers of the oral cavity, oropharynx, hypopharynx and larynx, account for over 700000 new cases diagnosed and over 350000 deaths each year, representing $4 \%$ of all new cancers in Europe and South America. ${ }^{1}{ }^{2}$ Worldwide, trends of these cancers are on the rise-particularly in the oropharyngeal cancer subsite. ${ }^{3-5}$

The major risk factors for head and neck cancer are tobacco use and alcohol consumption (particularly in combination), which comprise around $70 \%$ of the population attributable risk. ${ }^{67}$ Human papillomavirus (HPV) infection is an emerging risk factor for oropharyngeal cancer. ${ }^{89}$ Across all head and neck cancers, socioeconomic risk associations are comparable in magnitude to those of behavioural risk factors, with the greatest burden of head and neck cancer observed in those with the lowest incomes and education levels. ${ }^{10}$ Tobacco smoking and alcohol consumption explain approximately two-thirds of the socioeconomic relationship, and this association persists when controlling for smoking or alcohol behaviour and among never smokers and never alcohol drinkers. ${ }^{10}$ A previous systematic review and meta-analysis of published risk estimates found consistent elevated risk for oral cancer associated with low occupational socioeconomic position, ${ }^{11}$ and an earlier small case-control study of larynx cancer suggested the occupational socioeconomic relationship was partly explained by smoking, alcohol consumption and substantially attributed to occupational exposures. ${ }^{12}$

The relationship between occupational-related socioeconomic factors and head and neck cancer risk has not been examined in detail. Socioeconomic classification of occupations is multidimensional 
and includes measures of occupational social position, prestige and class. ${ }^{1314}$ While occupational social classifications are largely related to the income and/or educational attainment required for the job, occupational social prestige explicitly relates to ranking of jobs based on normative admiration or respect. ${ }^{15}$ Occupational socioeconomic prestige is derived from multiple factors such as psychosocial aspects, work stress, job control and social support networks. ${ }^{1314}$ Low relative to high and downward lifetime trajectories of occupational socioeconomic prestige have previously been linked with cancer risk $^{16}$ and particularly lung cancer in men. ${ }^{15}$

Here we investigate the risk associations of occupational social prestige, occupational socioeconomic position, and manual occupations for head and neck cancer. We thoroughly assess explanatory factors including smoking, alcohol and occupational exposures, and we explore differences in these risk associations by gender, global region, and head and neck cancer subsite.

\section{METHODS}

The original data studies of the International Head and Neck Cancer Epidemiology (INHANCE) Consortium (http:// inhance.iarc.fr/) have been described in detail elsewhere. ${ }^{6} 17$ Briefly, we used data from five frequency-matched case-control studies, which provided databases with occupational histories, containing occupational and industrial codes, in addition to the INHANCE pooled database (V.1.5). We included studies from Western Europe, ${ }^{18}$ Latin America, ${ }^{19}$ Germany (Heidelberg), ${ }^{20}$ and two studies from France (1989-1991) ${ }^{21}$ and (2001-2007), ${ }^{22}$ which were all multicentre studies except for the German study. Online supplemental file 1 shows the main characteristics of these studies. We omitted participants with missing information on smoking behaviour $(n=176)$, alcohol consumption $(n=218)$, and missing or largely incomplete occupational history data $(\mathrm{n}=1071)$.

Cases comprised cancers of the oral cavity, oropharynx, hypopharynx and larynx. Control participants were recruited either in hospitals (France (1989-1991), Latin America) or in the general population (France (2001-2007), Germany (Heidelberg)). Both types of recruitment were used in the Western Europe study (online supplemental file 1).

\section{Occupational socioeconomic position and prestige data}

We assigned indices of socioeconomic position and prestige on the basis of participants' occupational histories, which contained job periods already coded by the International Standard Classification of Occupations of 1968 (ISCO68). ${ }^{23}$ We considered occupational histories before retirement, reviewed all job periods, and deleted periods with missing or implausible information for ISCO68, start year or end year. We then excluded data of participants from the analysis if: their occupational history spanned less than 10 years, but only if they were also $>30$ years at the time of the study ${ }^{15}$; and if less than $50 \%$ of their job history had ISCO68 codes.

We assigned Treiman's Standard International Occupational Prestige Scale (SIOPS) to the job histories. ${ }^{24}$ SIOPS assigns prestige ratings to occupations, ranging from 14 (lowest prestige, for example, unspecified and unskilled agricultural workers) to 78 (highest prestige, for example, physicians). Based on the distribution of SIOPS scores among controls, we categorised the SIOPS score range into quartiles (14-30, 31-39, 40-48, 49-78). We also coded the jobs to the International Socio-Economic Index of occupational position (ISEI) in the version corresponding to ISCO68, ${ }^{25}$ which comprises scores with a range from 10 (lowest position, for example, cook's helpers) to 90 (highest position, judges). As for SIOPS, we constructed quartiles based on the ISEI distribution in the control group (10-31, 32-39, 40-55, 56-90). Both, SIOPS and ISEI, were assigned on the basis of three-digit levels of ISCO68 codes. We further applied ISCO68 codes to manual and non-manual job groupings as previously described. ${ }^{26}$ For analyses, from the coded occupational histories, we selected the longest held job for the primary analyses, but also assessed the first job, last job, the jobs with the highest ever reached SIOPS and ISEI scores, and 'ever employed in manual job', respectively.

Occupational data were further used to represent occupational exposure to carcinogens for head and neck cancer. We integrated the investigated ISCO68 categories in a new list of risk occupations (online supplemental file 2) where (a) ORs for the comparison of ever versus never having worked in an ISCO68 occupation were elevated and (b) if ORs were increasing for 10 or more years of employment. Our job history data did not contain sufficient information to accurately assign industries and assess their risk associations. Although based on results for men, we applied the new list of risk occupations to both men and women. We distinguished whether participants were ever employed in risk occupations for 10 or more years. ${ }^{27} 28$ Finally, based on additional coding from three studies (Western Europe, France (2001-2007) and Germany (Heidelberg)), we characterised participants as ever or never having experienced unemployment.

\section{Statistical analysis}

We investigated head and neck cancer risk associations with occupational socioeconomic prestige, position, manual versus non-manual occupation and unemployment experience. We estimated ORs with 95\% CIs by unconditional logistic regression. Based on a model adjusting for sex, age (years) and study centre (model 1), we added further variables in cumulative steps to study the impact on the investigated association. We first added cigarette smoking behaviour (smoking status (never, former, current), duration (years), smoking intensity (average daily amount of cigarettes) and cigarette pack-years (model 2)). Never smokers were participants who had smoked less than 100 cigarettes during their lifetime. Former smokers were participants who quit smoking more than 1 year before study participation. In the next step, we additionally considered alcohol consumption (model 3) by adjusting for drinking status (ever/ never), drinking intensity, that is, average amount of alcoholic drinks per day ( $15.6 \mathrm{~mL}$ of ethanol per drink), and an interaction term of smoking (duration) and alcohol (intensity). ${ }^{6}$ We further adjusted for ever/never employed in a risk occupation (at least 10 years) ('full' model 4 ).

\section{Sensitivity and stratified analyses}

We further adjusted for the respective other socioeconomic position and prestige variables (SIOPS, ISEI, manual/non-manual) (model 5). We applied model 5 to analyse unemployment, but did not adjust for unemployment due to the missing data. The main analyses were based on the longest held job. Additional sensitivity analyses involved using the first and the last job as well as the highest ever reached SIOPS/ISEI or 'ever employment in manual job', respectively. We alternatively included SIOPS and ISEI as continuous variables. All further analyses were also based on SIOPS for the longest job and the 'full' model. Analyses were stratified by sex, tumour subsite (oral cavity, oropharynx, hypopharynx, larynx), study region (Europe, Latin America), 
type of control recruitment (hospital or population-based), and single as well as combined stratification for ever or never use of cigarettes and alcohol. Further sensitivity analyses included exploring differences observed by study regions; and-using model 1-examining those participants who were initially excluded because of largely incomplete occupational histories. Finally, we performed multiple imputation on missing smoking and alcohol information (predicted on respective available smoking and alcohol data by age, sex and study centre), and recalculated model 4. All analyses were performed with SAS V.9.4 (SAS Institute).

\section{RESULTS}

We included 13144 participants (5818 cases, 7326 controls) in the final analysis. Table 1 describes the study population. Lower categories of socioeconomic position and prestige indices were more frequent among cases. Only about one-third of overall cases had longest held jobs in the first or second quartiles of SIOPS and ISEI, respectively, whereas this proportion was about $50 \%$ among controls. Overall, $36 \%$ of cases compared with $22 \%$ of controls had ever worked in a risk occupation for at least 10 years, with lower proportions for women. Unemployment experience (data available for three of the five studies; approximately three-quarters of participants) was slightly higher for male cases than male controls.

Associations of occupational socioeconomic position and prestige are shown in table 2. For all indices, ORs increased with lower position/prestige. ORs were attenuated by all further adjustments, with the greatest effect through adjustment for cigarette smoking. Adjustment for alcohol consumption and employment in risk occupations only marginally reduced risk estimates. After adjustment for all behaviours and risk occupations, strong associations between low position/prestige and head and neck cancer persisted, with ORs for the lowest relative to highest categories of SIOPS: 1.88 (95\% CI: 1.64 to 2.17), ISEI: 1.74 (95\% CI: 1.51 to 1.99 ) and manual occupations: 1.49 (95\% CI: 1.35 to 1.64$)$. Accordingly, SIOPS and ISEI on a continuous scale were significant parameters in the fully adjusted model (online supplemental file 3 ).

In the model, mutually adjusting for other socioeconomic measures, SIOPS risk association remained OR 1.59 (95\% CI: 1.30 to 1.94 ). Additional, sensitivity analyses showed risk associations were slightly lower for the first job, and elevated for the last job and highest SIOPS and ISEI (online supplemental file 4). The subgroup analysis of participants who had ever experienced unemployment showed slightly elevated risks for head and neck cancer in the fully adjusted model.

Results for the stratified analyses of risk associations are shown in table 3A,B for SIOPS, and in online supplemental file $5 \mathrm{~A}, \mathrm{~B})$ for both ISEI and manual/non-manual occupation. The risk associations were consistently lower for women than men. In contrast to the European studies, we did not find a similar strength of association in Latin America. When we stratified by tumour subsite, we found stronger associations for cancer of the larynx (OR 1.96 (95\% CI: 1.60 to 2.42$)$ ) and hypopharynx (OR 2.61 (95\% CI: 1.92 to 3.55$)$ ) than oral cavity (OR 1.63 (95\% CI: 1.27 to 2.09 )) or oropharynx (OR 1.68 (95\% CI: 1.34 to 2.11)). Stratification by type of control recruitment showed increased ORs for population-based recruitment, and reduced ORs for hospital-based recruitment. Risk associations for low relative to high SIOPS reduced among never smokers and never alcohol drinkers (combined), with greater attenuation associated with never smokers (only) than never drinkers (only). Sensitivity analysis including participants initially excluded due to largely incomplete occupational histories did not change estimates, either for Europe or for Latin America; nor did multiple imputation for missing smoking and alcohol information only marginally changed estimates (data not shown).

\section{DISCUSSION}

We found consistently elevated risk associations for head and neck cancer with low occupational social prestige, low occupational socioeconomic position and manual work. These findings were only partly explained by smoking, alcohol drinking or working in recognised higher risk occupations. However, among the small subgroup of never smokers and never drinkers, the risks associated with lower social prestige and class were completely attenuated. The overall findings were stronger among men than women, for cancers of the larynx and hypopharynx, and observed in Europe, but not in Latin America.

Inequalities in health outcomes (including cancer) are driven by social determinants-by inequalities in income, wealth and power. ${ }^{29}$ Our analysis taps into several of these domains, particularly the power relationships that arise from different occupational strata (captured here by social prestige), and shown to be important in health outcomes. ${ }^{30}$

SIOPS is based on the social prestige given to different occupational groupings. McCartney et al recently reappraised theories of social class and their application to the study of health inequalities. ${ }^{31}$ They noted that SIOPS and ISEI, unlike traditional categorical occupational social class schemes, employ a continuous or gradational hierarchy-based on relative social advantage. $^{32}$ While ISEI captures more material aspects of socioeconomic position, as it is derived from education and income aspects of occupations, the use of the SIOPS ('prestige') measure enables more direct inference of the psychosocial dimension. ${ }^{13-16}$ Although SIOPS, ISEI and manual versus nonmanual reflect different socioeconomic 'class' dimensions, they all are occupation-based indices and are known to be strongly correlated. ${ }^{25}$ We found the strongest head and neck cancer risk associations for prestige, with socioeconomic position and manual occupations slightly lower. This points to the importance of psychosocial and material dimensions of occupational socioeconomic relationship with head and neck cancer, although the environmental aspect is also relevant.

While there are recognised head and neck cancer risk associations with certain occupations, ${ }^{27}$ we found only a limited inter-relationship between occupational risk and the socioeconomic dimensions of occupations. Earlier studies suggested that occupational exposures were responsible for about one-third of total cancer difference between high and low socioeconomic groups. ${ }^{33}$ In our data, for head and neck cancer, occupational exposures attenuated the socioeconomic excess risk associations (model 4 vs model 3 ) by around $20 \%$. However, this type of comparison of estimates may be biased in logistic regression models. ${ }^{34} 35$

Smoking is undoubtedly a major risk factor for head and neck cancer ${ }^{6}$ and a major explanatory factor for all socioeconomic health inequalities. ${ }^{10}$ Alcohol consumption also compounds head and neck cancer risk, ${ }^{67}$ and clustering of these risk factors is also observed in lower socioeconomic groups. ${ }^{11}$ We observed, following thorough adjustment of many dimensions of smoking and alcohol behaviours, that the risk associations with occupational socioeconomic measures reduced (but not fully). Elevated head and neck cancer risks associated with lower socioeconomic positions among never 


\section{Original research}

Table 1 Characteristics of participants by sex and case-control status

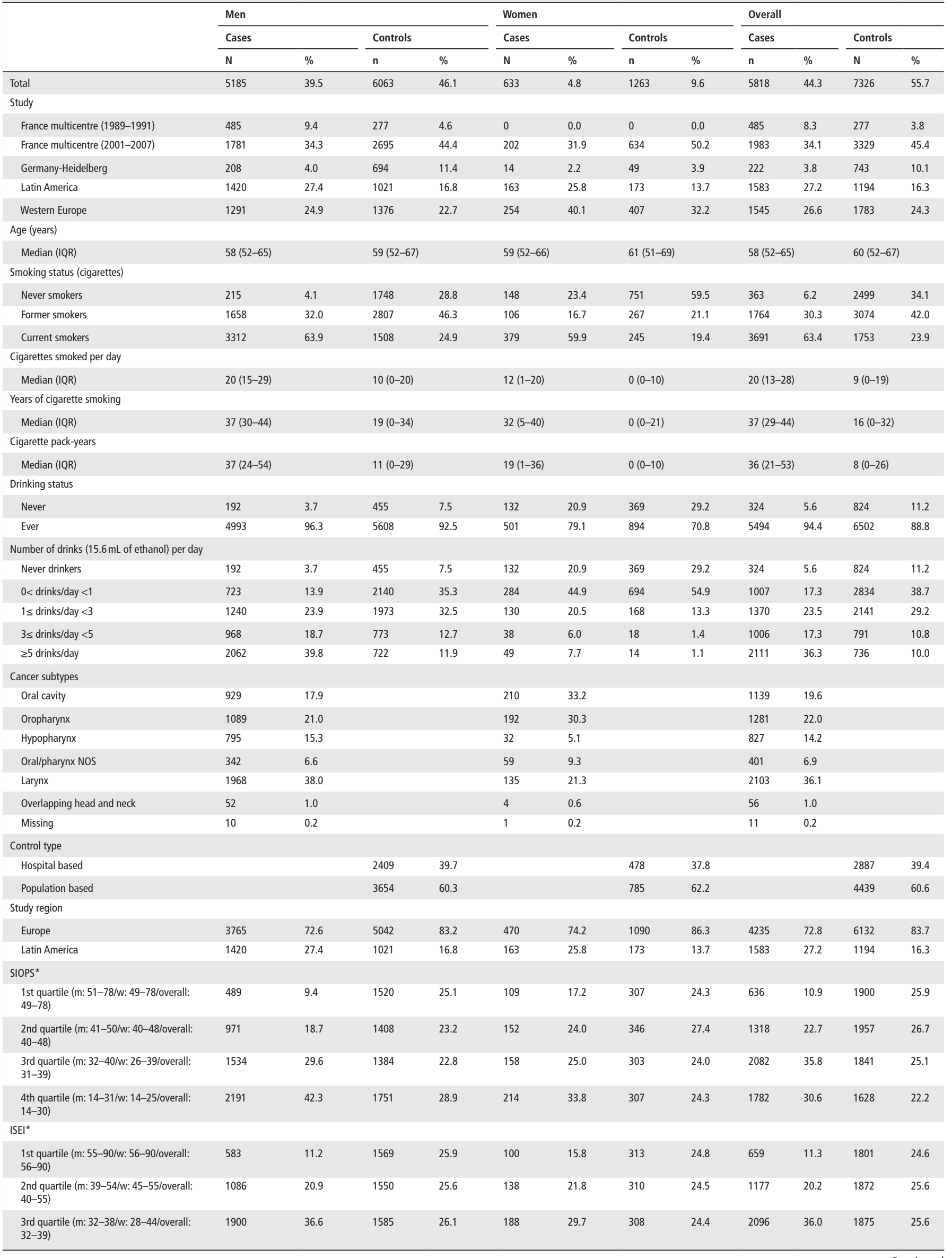


Table 1 Continued

\begin{tabular}{|c|c|c|c|c|c|c|c|c|c|c|c|c|}
\hline & \multicolumn{4}{|l|}{ Men } & \multicolumn{4}{|c|}{ Women } & \multicolumn{4}{|c|}{ Overall } \\
\hline & \multicolumn{2}{|l|}{ Cases } & \multicolumn{2}{|c|}{ Controls } & \multicolumn{2}{|c|}{ Cases } & \multicolumn{2}{|c|}{ Controls } & \multicolumn{2}{|c|}{ Cases } & \multicolumn{2}{|c|}{ Controls } \\
\hline & $\mathrm{N}$ & $\%$ & n & $\%$ & $\mathrm{~N}$ & $\%$ & $\mathbf{n}$ & $\%$ & $\mathbf{n}$ & $\%$ & $\mathrm{~N}$ & $\%$ \\
\hline 4th quartile (m:10-31/w:10-27/overall: 10-31) & 1616 & 31.2 & 1359 & 22.4 & 207 & 32.7 & 332 & 26.3 & 1886 & 32.4 & 1778 & 24.3 \\
\hline \multicolumn{13}{|l|}{ Longest job was manual } \\
\hline Yes & 3993 & 77.0 & 3503 & 57.8 & 398 & 62.9 & 642 & 50.8 & 4391 & 75.5 & 4145 & 56.6 \\
\hline No & 1192 & 23.0 & 2560 & 42.2 & 235 & 37.1 & 621 & 49.2 & 1427 & 24.5 & 3181 & 43.4 \\
\hline \multicolumn{13}{|l|}{ Worked $\geq 10$ years in risk occupations } \\
\hline Yes & 1947 & 37.6 & 1418 & 23.4 & 138 & 21.8 & 213 & 16.9 & 2085 & 35.8 & 1631 & 22.3 \\
\hline No & 3238 & 62.4 & 4645 & 76.6 & 495 & 78.2 & 1050 & 83.1 & 3733 & 64.2 & 5695 & 77.7 \\
\hline \multicolumn{13}{|l|}{ Ever experienced unemployment $†$} \\
\hline Yes & 402 & 12.3 & 345 & 7.2 & 42 & 8.9 & 83 & 7.6 & 444 & 11.8 & 428 & 7.3 \\
\hline No & 2878 & 87.7 & 4420 & 92.8 & 428 & 91.1 & 1007 & 92.4 & 3306 & 88.2 & 5427 & 92.7 \\
\hline
\end{tabular}

*Status/prestige score for longest job, categories by sex specific and overall quartiles of control group.

tNo data availa for Latin America and France (1989-1991).

ISEI, International Socio-Economic Index; NOS, not otherwise specified; SIOPS, Standard International Occupational Prestige Scale.

smokers and/or never alcohol drinkers suggest some potential residual effects of smoking and alcohol consumption. However, it should be noted that there are very small numbers of never smokers and never drinkers which make this estimate less reliable. Non-linearity of smoking and alcohol could risk misspecification and residual confounding ${ }^{36}$ - we undertook a post-hoc analysis with log-transformed smoking and alcohol variables which did not change the socioeconomic factors' risk association (data not shown). Stronger socioeconomic risk associations for hypopharynx and larynx cancers compared with oral cavity and oropharynx cancers point to a dominant role of smoking in explaining these associations. A previous INHANCE analysis showed that smoking had a significantly greater risk association for laryngeal cancer than oral cavity/ pharynx cancer. ${ }^{37}$ However, because alcohol and smoking are highly correlated, when adjusting for smoking, there is likely to be some adjustment for alcohol drinking, so alcohol's role in contributing to inequalities in head and neck cancer cannot be discounted.

Health inequalities and cancer risks associated with socioeconomic factors have generally been observed to be stronger among men than women. ${ }^{38}$ Our study is no exception, the likely explanations include lack of data in women, and particular difficulties in older generations in classifying women by occupational social classifications, ${ }^{13}$ reflected in the male database that was used for construction of SIOPS/ISEI. ${ }^{24} 25$ Suggestions that health inequalities affect women to a lesser degree are increasingly recognised as unfounded. ${ }^{39} 40$

Our finding of a lower risk association in Latin America was unexpected as it contradicted those of the original publication of socioeconomic analysis of the data ${ }^{40}$ - which found elevated ORs associated with non-manual ('social class') occupations. The socioeconomic distribution of controls was different from the other studies, that is, the Latin American controls were generally

Table 2 Adjusted ORs and 95\% Cls for the association between occupational socioeconomic measures and socioeconomic status and head and neck cancer

\begin{tabular}{|c|c|c|c|c|c|c|c|}
\hline & Cases & Controls & Model 1* OR $(95 \% \mathrm{Cl})$ & Model $2+$ OR $(95 \% \mathrm{Cl})$ & Model 3‡ OR $(95 \% \mathrm{Cl})$ & Model 4§ OR $(95 \% \mathrm{Cl})$ & Model 5ा OR $(95 \% \mathrm{Cl})$ \\
\hline \multicolumn{8}{|l|}{ SIOPS** } \\
\hline 1st quartile (49-78) & 636 & 1900 & 1.00 & 1.00 & 1.00 & 1.00 & 1.00 \\
\hline 2nd quartile (40-48) & 1318 & 1957 & 1.89 (1.68 to 2.12 ) & 1.59 (1.39 to 1.81$)$ & 1.57 (1.38 to 1.80$)$ & 1.55 (1.36 to 1.76$)$ & 1.45 (1.23 to 1.71$)$ \\
\hline 3rd quartile (31-39) & 2082 & 1841 & 2.79 (2.49 to 3.13$)$ & 2.00 (1.76 to 2.27 ) & 1.95 (1.72 to 2.22 ) & 1.82 (1.59 to 2.07 ) & 1.58 (1.30 to 1.92$)$ \\
\hline 4th quartile (14-30) & 1782 & 1628 & 2.77 (2.46 to 3.12 ) & 2.12 (1.86 to 2.42 ) & 2.08 (1.82 to 2.37 ) & 1.88 (1.64 to 2.17 ) & 1.59 (1.30 to 1.94$)$ \\
\hline \multicolumn{8}{|l|}{$|S E|^{* *}$} \\
\hline 1st quartile (56-90) & 659 & 1801 & 1.00 & 1.00 & 1.00 & 1.00 & 1.00 \\
\hline 2nd quartile (40-55) & 1177 & 1872 & 1.64 (1.46 to 1.85$)$ & 1.43 (1.25 to 1.63$)$ & 1.42 (1.24 to 1.62 ) & 1.38 (1.21 to 1.58$)$ & 1.01 (0.85 to 1.20$)$ \\
\hline 3rd quartile (32-39) & 2096 & 1875 & 2.49 (2.22 to 2.79$)$ & 1.85 (1.63 to 2.10$)$ & 1.80 (1.59 to 2.05$)$ & 1.68 (1.47 to 1.91$)$ & 1.05 (0.84 to 1.31$)$ \\
\hline 4th quartile (10-31) & 1886 & 1778 & 2.45 (2.19 to 2.76 ) & 1.98 (1.73 to 2.25$)$ & 1.93 (1.69 to 2.20$)$ & 1.74 (1.51 to 1.99$)$ & 1.11 (0.88 to 1.40$)$ \\
\hline \multicolumn{8}{|l|}{ Ever manual job } \\
\hline No & 1427 & 3181 & 1.00 & 1.00 & 1.00 & 1.00 & 1.00 \\
\hline Yes & 4391 & 4145 & 1.99 (1.83 to 2.15$)$ & 1.64 (1.50 to 1.80$)$ & 1.61 (1.47 to 1.76$)$ & 1.49 (1.35 to 1.64$)$ & 1.15 (0.99 to 1.34$)$ \\
\hline \multicolumn{8}{|l|}{ Ever unemployed $t \dagger$} \\
\hline No & 3306 & 5427 & 1.00 & 1.00 & 1.00 & 1.00 & 1.00 \\
\hline Yes & 444 & 428 & 1.85 (1.60 to 2.13$)$ & 1.37 (1.16 to 1.61$)$ & 1.26 (1.06 to 1.50$)$ & 1.24 (1.04 to 1.47$)$ & 1.19 (1.00 to 1.41$)$ \\
\hline
\end{tabular}

*Adjustment for sex, age and study centre.

†Variables of model 1 and further adjustment for cigarette smoking (status, duration, cigarettes/day, pack-years).

¥Variables of model 2 and further adjustment for alcohol consumption (status, drinks/day, interaction drinks/day $x$ duration cigarette smoking).

$\S$ Variables of model 3 and further adjustment for worked $\geq 10$ years in risk occupations (10years before study).

IVariables of model 4 and further adjustment for respective other SES/prestige variables (SIOPS, ISEI, manual/non-manual).

**Scores for longest job, categories based on quartiles of control distribution.

††No data available for Latin America and France (1989-1991).

ISEI, International Socio-Economic Index; SES, socioeconomic status; SIOPS, Standard International Occupational Prestige Scale. 


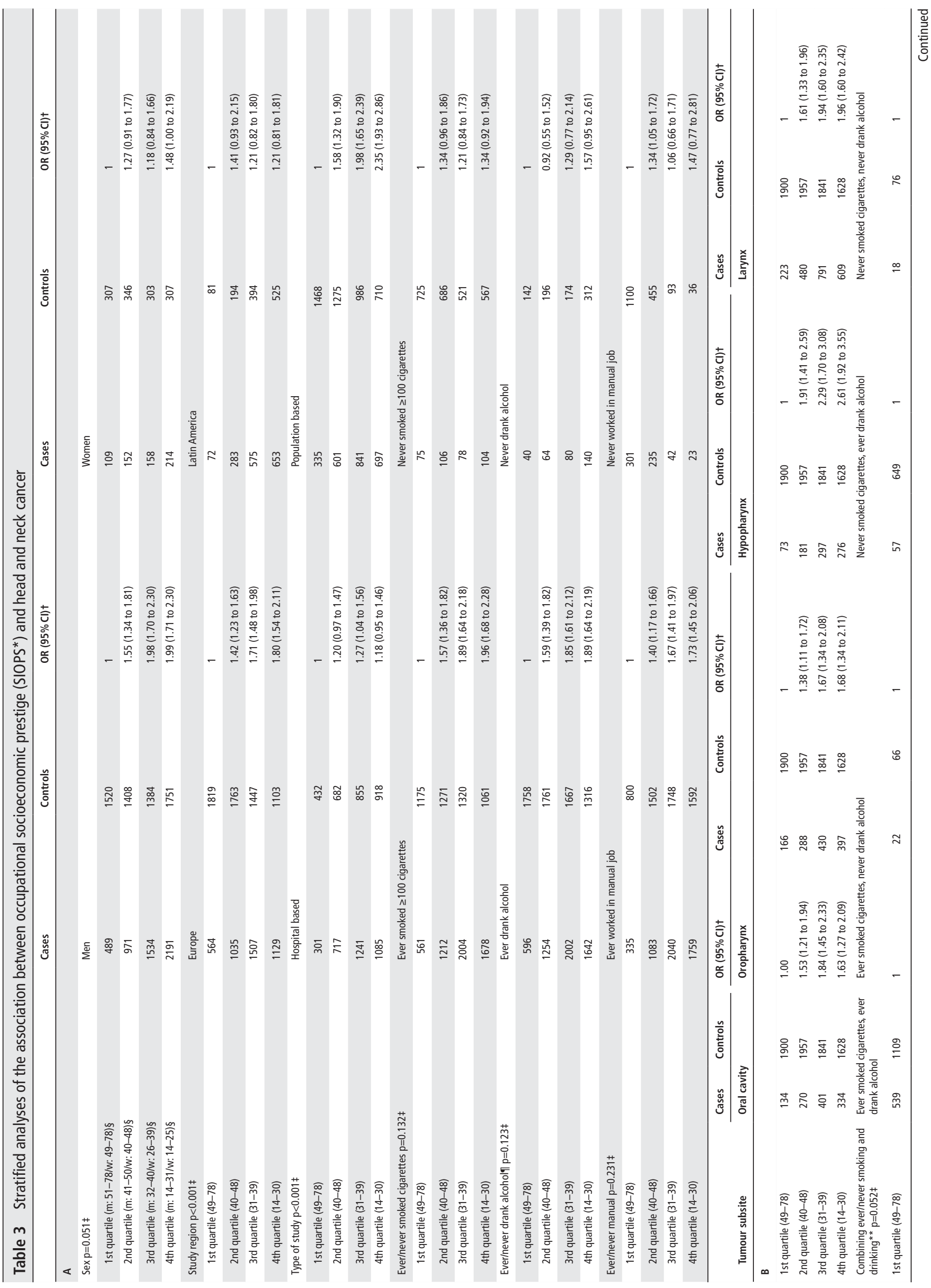


from lower socioeconomic groups, and more similar to the case distribution. Post-hoc analysis, building SIOPS/ISEI quartiles based on the Latin American control distribution (rather than overall control distribution) did not change the findings. The Latin American study employed hospital controls, which we found overall had lower risks (consistent across SIOPS and ISEI). In a further post-hoc analysis, removing the Latin America data from the stratified analysis, the ORs for hospital controls did not change, which could indicate that type of recruitment accounted for the difference rather than study region. Moreover, this continental difference observed was unlikely to be due to conceptual sociological differences in the measures across the countries-as SIOPS has been shown to be stable across very diverse cultures, ${ }^{24}$ and ISEI was validated internationally (including Brazil). ${ }^{25}$

Our study has several strengths, including the relatively large size with nearly 6000 cases and over 7000 controls from five robust well-designed multicentre case-control studies with harmonised data. ${ }^{17} 41$ The large size of the study with good quality socioeconomic and behavioural risk factor data enabled risk estimates to be examined and confounders to be thoroughly adjusted for. Analyses method strengths included multiple sensitivity analyses to test the robustness of the results.

There were also limitations of this study including unquantifiable measurement errors, data availability limitations and residual confounding. We were only able to include 5 of the possible 35 studies in INHANCE, with no studies from North America or indeed South Asia. ${ }^{41}$ Included studies had to have prior ISCO-coded occupational histories. The occupational risks derived from these codes are probably too imprecise to indicate specific exposure to occupational carcinogens, so residual confounding is a possibility. It was also not possible to examine the industrial dimensions of occupations in this study as have previously been shown to be related to socioeconomic inequalities in cancer incidence. ${ }^{42} 43$ Lifetime duration of alcohol (even over a short period) has begun to be shown to increase cancer risk, ${ }^{44}$ however, this variable was missing from some of the studies and could not be included in the analysis. Data on HPV were also not available for the studies in this analysis and could be an important factor particularly in relation to oropharyngeal risks. $^{89}$ Recall bias is also a possibility, although it is unlikely that cases reported their occupational history differently from controls. ${ }^{27}$ In addition, periods of housework or part-time work (more common among women) were excluded and could have underestimated socioeconomic effects. ${ }^{45}$ Selection bias could potentially impact the findings particularly in the hospitalbased centres where the controls are potentially of similar socioeconomic and risk behaviour profiles to the case participants. Indeed, our findings were stronger in study centres with population-based design. Previous INHANCE socioeconomic analyses of income and education found no differences between hospital and population-based controls reassuring against the risk of selection bias, and the measures undertaken in the studies which used hospital-based control sampling to reduce selection bias included recruiting patients attending hospital not for cancer nor conditions related to the main behavioural risk factors. ${ }^{10}$ Finally, SIOPS and ISEI have not been updated since their creation in the late 20th century, and may not reflect recent occupational socioeconomic structures. However, the indices used were appropriate for the decades when most of the participants were employed, and job ranking by SIOPS has been shown to be consistent over time. ${ }^{24}$ There has been a general shift from manual to low-level service occupations which may not be captured by these socioeconomic measures, although this would have had a minimal impact as our data were largely collected in 
the early 2000s (with mean participant age of 50-60 years) and further analyses of trajectories of occupational socioeconomic prestige could be subsequently undertaken.

\section{CONCLUSIONS}

Our results indicate that occupational socioeconomic prestige, position and manual work are associated with head and neck cancer, and this risk is only partly explained by smoking and alcohol exposure. Occupational exposures were not a major explanatory factor as expected given the occupational source of our socioeconomic measures. This points to the importance of psychosocial impacts of socioeconomic factors as well as the more recognised material dimension in head and neck cancer risk. The implications of these results could also extend to the inclusion of psychosocial/socioeconomic occupational factors in the future development of head and neck cancer risk assessment/ prediction tools, and to informing prevention and early detection efforts.

\section{What is already known on this subject}

- The association between socioeconomic disadvantage (measured by low education and/or income) and head and neck cancer risk is well established.

- Less is known on the risks of head and neck cancer associated with socioeconomic aspects of occupations and the inter-relationship with occupational exposures.

\section{What this study adds}

- Low occupational socioeconomic prestige and position, and manual work are associated with head and neck cancer, and such risks are only partly explained by smoking, alcohol and occupational exposures.

- Perceptual occupational psychosocial status (Standard International Occupational Prestige Scale) appears to be strongest socioeconomic factors relative to socioeconomic position and manual/non-manual work.

- Implications could extend to the inclusion of psychosocioeconomic occupational factors in future development of head and neck cancer risk prediction tools, and to informing prevention and early detection strategies.

\section{Author affiliations}

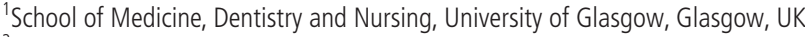
${ }^{2}$ Institute for Prevention and Occupational Medicine of the German Social Accident Insurance (IPA), Ruhr University Bochum, Bochum, Nordrhein-Westfalen, Germany ${ }^{3}$ Leibniz Institute for Prevention Research and Epidemiology, Bremen, Germany ${ }^{4}$ Institute of Hygiene and Epidemiology, Charles University First Faculty of Medicine, Praha, Czech Republic

${ }^{5}$ School of Medicine, National and Kapodistrian University of Athens, Athens, Attica, Greece

${ }^{6}$ Oncology Reference Center, Aviano, Friuli-Venezia Giulia, Italy

${ }^{7}$ Department of Cardiac, Thoracic and Vascular Sciences and Public Health, University of Padua, Padova, Veneto, Italy

${ }^{8}$ Department of Medical Sciences, University of Turin, Torino, Piemonte, Italy

${ }^{9}$ School of Dental Science, Trinity College Dublin, Dublin, Ireland

${ }^{10}$ Cancer Registry of Norway, Oslo, Norway

${ }^{11}$ Epidemiology Group, University of Aberdeen, Aberdeen, UK

${ }^{12}$ Faculty of Dentistry, University of Hong Kong, Hong Kong, Hong Kong

${ }^{13}$ Unit of Nutrition and Cancer, Cancer Epidemiology Research Program, Catalan

Institute of Oncology, Hospitalet de Llobregat, Catalunya, Spain

${ }^{14}$ International Agency for Research on Cancer, Lyon, Rhône-Alpes, France

${ }^{15}$ University of Rennes 1 - Health Sciences Campus Villejean, Rennes, Bretagne, France
${ }^{16}$ Institute for Research in Health, Environment and Work, National Institute of Health and Medical Research, Rennes, Bretagne, France

${ }^{17}$ School of Advanced Studies in Public Health, Rennes, Bretagne, France

${ }^{18}$ Sorbonne Université, INSERM, Institut Pierre Louis d'Epidémiologie et de Santé

Publique, Paris, France

${ }^{19}$ Paris-Sud University, Saint-Aubin, Île-de-France, France

${ }^{20}$ Environmental Epidemiology of Cancer, Centre for Research in Epidemiology and Population Health, National Institute of Health and Medical Research, Villejuif, Île-de-

France, France

${ }^{21}$ Gustave-Roussy Institute, Villejuif, Île-de-France, France

${ }^{22}$ Institute of Public Health, University of Heidelberg, Heidelberg, Baden-

Württemberg, Germany

${ }^{23}$ The Tisch Cancer Institute and Institute for Translational Epidemiology, Mount Sinai

School of Medicine, New York, New York, USA

${ }^{24}$ Department of Medical and Surgical Sciences, University of Bologna, Bologna,

Emilia-Romagna, Italy

${ }^{25}$ Institute of Oncology Angel H Roffo, University of Buenos Aires, Buenos Aires, Argentina

${ }^{26}$ National Institute of Oncology and Radiobiology, La Habana, Cuba

${ }^{27}$ Epidemiology, AC Camargo Cancer Center International Research Center, Sao Paulo, Brazil

${ }^{28}$ Federal University of Pelotas, Pelotas, Rio Grande do Sul, Brazil

${ }^{29} \mathrm{Hospital}$ de Clinicas de Porto Alegre, Porto Alegre, Rio Grande do Sul, Brazil

${ }^{30}$ Fundacao Oswaldo Cruz, National School of Public Health, Rio de Janeiro, Brazil

${ }^{31}$ University of Sao Paulo, Sao Paulo, Brazil

${ }^{32}$ Division of Public Health, Department of Family and Preventive Medicine and Huntsman Cancer Institute, University of Utah School of Medicine, Salt Lake City, Utah, USA

${ }^{33}$ Division of Public Health, Department of Family and Preventive Medicine, Huntsman Cancer Institute, Salt Lake City, Utah, USA

\section{Twitter David I Conway @davidiconway}

Contributors DIC conceived the study. DIC, ADM, TB, JH, AR and WA designed the study. JH with ADM and TB performed analysis. MH and ALY-C coordinated pooled data. All authors (DIC, JH, WA, AR, IH, PL, DS, CC, LR, CH, KK, GJM, PT, $A A, A Z, P B, D L, G M, I S, S B, H R, P B, M V$, LF, MPC, AM, AD, RK, VW-F, ALY-C, MH, TB, ADM) reviewed analysis proposal and plan. DIC, TB, JH, AR and ADM drafted the manuscript. All authors read and reviewed the final manuscript. DIC is responsible for the overall content as guarantor.

Funding This work was supported by funders of the original studies. ARCAGE (Western Europe): European Community (5th Framework Programme) grant no QLK1-CT-2001-00182; France study: Swiss League against Cancer (KFS1069-092000), Fribourg League against Cancer (FOR381.88), Swiss Cancer Research (AKT 617) and Gustave-Roussy Institute (88D28); Germany-Heidelberg study: German Ministry of Education and Research (No. 01GB9702/3); Latin American study: Fondo para la Investigacion Cientifica y Tecnologica (FONCYT) Argentina, IMIM (Barcelona), Fundaco de Amparo a Pesquisa no Estado de Sao Paulo (FAPESP) (No. 01/017682), and European Commission (IC18-CT97-0222); INHANCE Pooled Data Project: NCI (R03CA113157, NIDCR R03DE016611). ICARE (France 2001-2007): French National Research Agency (ANR); French National Cancer Institute (INCA); French Agency for Food, Environmental and Occupational Health and Safety (ANSES); French Institute for Public Health Surveillance (InVS); Fondation pour la Recherche Médicale (FRM); Fondation de France; Fondation ARC pour la Recherche sur le Cancer; French Ministry of Labour (Direction Générale du Travail); French Ministry of Health (Direction Générale de la Santé).

Competing interests None declared.

\section{Patient consent for publication Obtained.}

Ethics approval Ethical approval was obtained from appropriate institutional local review boards and all participants provided written informed consent for the original studies.

Provenance and peer review Not commissioned; externally peer reviewed.

Data availability statement Data are available upon reasonable request. Data are available from the corresponding author, DIC, upon reasonable request, with the permission of the INHANCE Consortium.

Supplemental material This content has been supplied by the author(s). It has not been vetted by BMJ Publishing Group Limited (BMJ) and may not have been peer-reviewed. Any opinions or recommendations discussed are solely those of the author(s) and are not endorsed by BMJ. BMJ disclaims all liability and responsibility arising from any reliance placed on the content. Where the content includes any translated material, BMJ does not warrant the accuracy and reliability of the translations (including but not limited to local regulations, clinical guidelines, terminology, drug names and drug dosages), and is not responsible for any error and/or omissions arising from translation and adaptation or otherwise. 
Open access This is an open access article distributed in accordance with the Creative Commons Attribution Non Commercial (CC BY-NC 4.0) license, which permits others to distribute, remix, adapt, build upon this work non-commercially, and license their derivative works on different terms, provided the original work is properly cited, appropriate credit is given, any changes made indicated, and the use is non-commercial. See: http://creativecommons.org/licenses/by-nc/4.0/.

\section{ORCID iDs}

David I Conway http://orcid.org/0000-0001-7762-4063

Jan Hovanec http://orcid.org/0000-0003-1811-1465

Wolfgang Ahrens http://orcid.org/0000-0003-3777-570X

Alastair Ross http://orcid.org/0000-0003-2952-3182

Ivana Holcatova http://orcid.org/0000-0002-1366-0337

Diego Serraino http://orcid.org/0000-0003-0565-8920

Cristina Canova http://orcid.org/0000-0001-7027-7935

Lorenzo Richiardi http://orcid.org/0000-0003-0316-9402

Claire Healy http://orcid.org/0000-0001-7940-4611

Kristina Kjaerheim http://orcid.org/0000-0003-0691-3735

Gary J Macfarlane http://orcid.org/0000-0003-2322-3314

Peter Thomson http://orcid.org/0000-0002-2007-7975

Antonio Agudo http://orcid.org/0000-0001-9900-5677

Ariana Znaor http://orcid.org/0000-0002-0518-8714

Danièle Luce http://orcid.org/0000-0002-1708-4584

Gwenn Menvielle http://orcid.org/0000-0002-3261-6366

Simone Benhamou http://orcid.org/0000-0001-5853-8047

Heribert Ramroth http://orcid.org/0000-0001-5958-1717

Paolo Boffetta http://orcid.org/0000-0002-3811-2791

Maria Paula Curado http://orcid.org/0000-0001-8172-2483

Ana Menezes http://orcid.org/0000-0002-2996-9427

Rosalina Koifman http://orcid.org/0000-0002-2746-7597

Thomas Behrens http://orcid.org/0000-0002-4583-5234

Alex D McMahon http://orcid.org/0000-0002-9425-7792

\section{REFERENCES}

1 El-Naggar AK, Chan JKC, Grandis JR. Who classification of head and neck tumours. 4th edn. Lyon: International Agency for Research on Cancer, 2017.

2 Ferlay J, Colombet M, Soerjomataram I. Global and regional estimates of the incidence and mortality for 38 cancers: GLOBOCAN 2018. Lyon: International Agency for Research on Cancer, 2018. http://globocan.iarc.fr

3 Chaturvedi AK, Anderson WF, Lortet-Tieulent J, et al. Worldwide trends in incidence rates for oral cavity and oropharyngeal cancers. J Clin Oncol 2013;31:4550-9.

4 Purkayastha M, McMahon AD, Gibson J, et al. Trends of oral cavity, oropharyngeal and laryngeal cancer incidence in Scotland (1975-2012) - A socioeconomic perspective. Oral Oncol 2016:61:70-5.

5 Junor EJ, Kerr GR, Brewster DH. Oropharyngeal cancer. fastest increasing cancer in Scotland, especially in men. BMJ 2010;340:c2512.

6 Hashibe M, Brennan P, Benhamou S, et al. Alcohol drinking in never users of tobacco, cigarette smoking in never drinkers, and the risk of head and neck cancer: pooled analysis in the International head and neck cancer epidemiology Consortium. J Natl Cancer Inst 2007;99:777-89.

7 Anantharaman D, Marron M, Lagiou P, et al. Population attributable risk of tobacco and alcohol for upper aerodigestive tract cancer. Oral Oncol 2011;47:725-31.

8 D'Souza G, Kreimer AR, Viscidi R, et al. Case-Control study of human papillomavirus and oropharyngeal cancer. N Engl J Med 2007;356:1944-56.

9 Anantharaman D, Gheit T, Waterboer T, et al. Human papillomavirus infections and upper aero-digestive tract cancers: the ARCAGE study. J Nat/ Cancer Inst 2013;105:536-45.

10 Conway DI, Brenner DR, McMahon AD, et al. Estimating and explaining the effect of education and income on head and neck cancer risk: INHANCE Consortium pooled analysis of 31 case-control studies from 27 countries. Int J Cancer 2015;136:1125-39.

11 Conway DI, Petticrew M, Marlborough $\mathrm{H}$, et al. Socioeconomic inequalities and oral cancer risk: a systematic review and meta-analysis of case-control studies. Int I Cancer 2008:122:2811-9.

12 Menvielle G, Luce D, Goldberg P, et al. Smoking, alcohol drinking, occupational exposures and social inequalities in hypopharyngeal and laryngeal cancer. Int J Epidemiol 2004;33:799-806.

13 Galobardes B, Shaw M, Lawlor DA, et al. Indicators of socioeconomic position (Part 1). J Epidemiol Community Health 2006;60:7-12.

14 Galobardes B, Shaw M, Lawlor DA, et al. Indicators of socioeconomic position (Part 2). J Epidemiol Community Health 2006:60:95-101.

15 Behrens T, Groß I, Siemiatycki J, et al. Occupational prestige, social mobility and the association with lung cancer in men. BMC Cancer 2016;16:395.
16 Chida Y, Hamer M, Wardle J, et al. Do stress-related psychosocial factors contribute to cancer incidence and survival? Nat Clin Pract Oncol 2008:5:466-75.

17 Conway DI, Hashibe M, Boffetta P, et al. Enhancing epidemiologic research on head and neck cancer: INHANCE - The international head and neck cancer epidemiology consortium. Oral Oncol 2009;45:743-6

18 Lagiou P, Georgila C, Minaki P, et al. Alcohol-Related cancers and genetic susceptibility in Europe: the ARCAGE project: study samples and data collection. Eur J Cancer Prev 2009;18:76-84.

19 Szymańska K, Levi JE, Menezes A, et al. TP53 and EGFR mutations in combination with lifestyle risk factors in tumours of the upper aerodigestive tract from South America. Carcinogenesis 2010;31:1054-9.

20 Ramroth $\mathrm{H}$, Dietz A, Becher $\mathrm{H}$. Environmental tobacco smoke and laryngeal cancer: results from a population-based case-control study. Eur Arch Otorhinolaryngol 2008;265:1367-71

21 Goldberg P, Leclerc A, Luce D, et al. Laryngeal and hypopharyngeal cancer and occupation: results of a case control-study. Occup Environ Med 1997;54:477-82.

22 Luce D, Stücker I, ICARE Study Group. Investigation of occupational and environmental causes of respiratory cancers (ICARE): a multicenter, population-based case-control study in France. BMC Public Health 2011:11:928.

23 International Labour Organization. International standard classification of occupations. Geneva, 1968. http://www.ilo.org/public/libdoc/ilo/1969/69B09_35_ engl.pdf

24 Treiman DJ. Occupational prestige in comparative perspective. New York: Academic Press, 1977.

25 Ganzeboom HBG, De Graaf PM, Treiman DJ. A standard international socio-economic index of occupational status. Soc Sci Res 1992;21:1-56.

26 Hrubá F, Fabiáová E, Bencko V, et al. Socioeconomic indicators and risk of lung cancer in central and eastern Europe. Cent Eur J Public Health 2009;17:115-21.

27 Richiardi L, Corbin M, Marron M, et al. Occupation and risk of upper aerodigestive tract cancer: the ARCAGE study. Int I Cancer 2012;130:2397-406.

28 Paget-Bailly S, Guida F, Carton M, et al. Occupation and head and neck cancer risk in men: results from the ICARE study, a French population-based case-control study. J Occup Environ Med 2013;55:1065-73.

29 Vaccarella S, Lortet-Tieulent J, Saracci R, et al. Reducing social inequalities in cancer: setting priorities for research. CA Cancer I Clin 2018;68:324-6.

30 Phelan JC, Link BG, Tehranifar P. Social conditions as fundamental causes of health inequalities: theory, evidence, and policy implications. J Health Soc Behav 2010;51:S28-40.

31 McCartney G, Bartley M, Dundas R, et al. Theorising social class and its application to the study of health inequalities. SSM Popul Health 2019;7:100315.

32 Connelly R, Gayle V, Lambert PS. A review of occupation-based social classifications for social survey research. Method Innov 2016;9:1-14.

33 Boffetta $\mathrm{P}$, Kogevinas M, Westerholm P, et al. Exposure to occupational carcinogens and social class differences in cancer occurrence. IARC Sci Publ 1997;138:331-41.

34 Hafeman DM. "Proportion explained": a causal interpretation for standard measures of indirect effect? Am J Epidemiol 2009;170:1443-8.

35 Jiang Z, VanderWeele TJ. When is the difference method conservative for assessing mediation? Am J Epidemiol 2015;182:105-8.

36 Leffondré K, Abrahamowicz M, Siemiatycki J, et al. Modeling smoking history: a comparison of different approaches. Am J Epidemiol 2002;156:813-23.

37 Lubin JH, Gaudet MM, Olshan AF, et al. Body mass index, cigarette smoking, and alcohol consumption and cancers of the oral cavity, pharynx, and larynx: modeling odds ratios in pooled case-control data. Am J Epidemiol 2010;171:1250-61.

38 Vâgerö D. Health inequalities in women and men. BMJ 2000;320:1286-7.

39 Menvielle $G$, Rey $G$, Jougla E, et al. Diverging trends in educational inequalities in cancer mortality between men and women in the 2000s in France. BMC Public Health 2013;13:823.

40 Boing AF, Antunes JLF, de Carvalho MB, et al. How much do smoking and alcoho consumption explain socioeconomic inequalities in head and neck cancer risk? J Epidemiol Community Health 2011:65:709-14.

41 Winn DM, Lee Y-CA, Hashibe M, et al. The INHANCE Consortium: toward a better understanding of the causes and mechanisms of head and neck cancer. Oral Dis 2015;21:685-93.

42 Zaitsu M, Kaneko R, Takeuchi T, et al. Occupational inequalities in female cancer incidence in Japan: hospital-based matched case-control study with occupational class. SSM Popul Health 2018;5:129-37.

43 Zaitsu M, Kaneko R, Takeuchi T, et al. Occupational class and male cancer incidence: nationwide, multicenter, hospital-based case-control study in Japan. Cancer Med 2019:8:795-813.

44 Zaitsu M, Takeuchi T, Kobayashi Y, et al. Light to moderate amount of lifetime alcohol consumption and risk of cancer in Japan. Cancer 2020;126:1031-40

45 Martikainen P, Valkonen T. Bias related to the exclusion of the economically inactive in studies on social class differences in mortality. Int J Epidemiol 1999:28:899-904. 